\title{
Contribuições do Pensamento Construcionista para o Estudo da Prática Grupal
}

\author{
Emerson F. Rasera \\ Marisa Japur ${ }^{12}$ \\ Universidade de São Paulo, Ribeirão Preto
}

\begin{abstract}
Resumo
O construcionismo, como forma de elaboração da crise paradigmática que têm vivido as ciências humanas, redimensiona várias concepções sobre a produção do conhecimento e os processos psicoterápicos. Neste artigo, buscaremos apontar como a ênfase nos processos relacionais e a centralidade da linguagem promovidas pelo construcionismo transformam o estudo da prática grupal. Através de um exemplo empírico, apontaremos algumas implicações metodológicas da aplicação dos pressupostos construcionistas ao estudo da prática grupal, tais como a explicitação do caráter construído do grupo e seu processo de negociação, a perspectiva discursiva de construção da pessoa e a conseqüente redefinição da homogeneidade grupal, e as delimitações sociais destes processos grupais. Finalizamos o artigo indicando outros desdobramentos teórico-metodológicos necessários ao desenvolvimento destas contribuições aos estudos dos grupos.

Palavras-chave: Construcionismo; psicoterapia de grupo; metodologia qualitativa.
\end{abstract}

Constructionist's Contributions for the Study of Group Work

\begin{abstract}
Social constructionism, as a human sciences paradigmatic crisis elaboration, rebuilds some conceptions of knowledge production and psychotherapeutic processes. In this article, we point out how the emphasis on the relational processes and the centrality of language promoted by constructionism change the study of group work. Using an empirical example, we consider some methodological implications of constructionist assumptions for the study of group work, as i) the constructed character of the group and its negotiating process, ii) the discursive approach of person construction and the consequent group homogeneity redefinition and iii) the social constraints of group processes. We conclude this article pointing out other theoretical and methodological developments necessary to unfold these contributions to group study.

Keywords: Constructionism; group psychotherapy; qualitative research.
\end{abstract}

\section{O Construcionismo}

O construcionismo, situado como uma forma específica de elaboração da crise paradigmática enfrentada pela ciência nas últimas décadas, tem desenvolvido um novo arcabouço teórico baseado em uma concepção não empiricista do funcionamento da ciência e suas formas de investigação. Suas origens podem ser remontadas, se quisermos, a um debate muito antigo travado entre empiristas e racionalistas. Contudo, para os objetivos deste texto, é importante dizer que foi nas últimas décadas que este movimento ganhou contornos mais nítidos e impôs

\footnotetext{
${ }^{1}$ Endereço para correspondência: Faculdade de Filosofia, Ciências e Letras de Ribeirão Preto da Universidade de São Paulo - Departamento de Psicologia e Educação. Avenida dos Bandeirantes, 3900. Campus da USP. 14090-910. Ribeirão Preto - SP. Brasil. E-mail: mjapur@fffclrp.usp.br ${ }^{2}$ Apoio: FAPESP
}

uma nova agenda de pesquisa. Através de diversas transformações - produzidas pelas críticas ideológicas da Escola de Frankfurt, e do movimento feminista, da crítica retórica-literária pós-estruturalista e das contribuições da sociologia do conhecimento -, a racionalidade e objetividade da ciência e sua visão do conhecimento enquanto um processo individual ganham novos contornos.

Um dos autores contemporâneos que têm contribuído na construção deste movimento na Psicologia é Kenneth Gergen (1985, 1997, 1999). Centraremos a definição do que vem a ser chamado construcionismo a partir da obra deste autor. Segundo Gergen, o construcionismo é uma forma de investigação social que “(...) preocupa-se principalmente em explicar os processos pelos quais as pessoas descrevem, explicam ou dão conta do mundo (incluindo elas mesmas) no qual elas vivem" (1985, p. 266). 
Para ele (Gergen, 1997), os seguintes pressupostos são centrais para uma perspectiva construcionista do conhecimento:

a) As descrições do mundo não guardam correspondência com uma realidade situada para além das formas de dizê-la, mas são elas próprias maneiras de construção desta realidade.

b) As descrições sobre o mundo são resultado da coordenação da ação humana, ou seja, dos significados construídos em relacionamentos. Estas descrições são produtos de trocas historicamente situadas entre as pessoas. Desta maneira, a possibilidade lógica de inúmeras formas de descrição da realidade é limitada pelas condições concretas das construções histórico-culturais dos sistemas de significação.

c) A permanência de determinadas descrições do mundo ao longo do tempo depende das vicissitudes dos processos sociais de negociação, comunicação, conflito e consenso, existentes em uma comunidade lingüística, e não de sua validade objetiva.

d) A linguagem deriva sua significação a partir das formas pelas quais funciona no interior de certos padrões de relacionamentos. Ou seja, o significado das palavras é decorrente do seu uso social, das formas pelas quais são utilizadas nos relacionamentos existentes.

e) Determinadas 'comunidades de inteligibilidade' podem produzir avaliações a respeito da credibilidade e aceitabilidade de certas afirmações a partir dos relacionamentos que as constituem. Contudo, os critérios de validade aí existentes não possibilitam a auto-avaliação, nem a avaliação do impacto de certos conjuntos de afirmações em outras comunidades próximas. Faz-se necessário então avaliar criticamente as diversas inteligibilidades a partir de uma outra posição, explorando seu impacto na cultura. A partir do momento que tais avaliações possam ser absorvidas pelas comunidades avaliadas, novas formas de diálogo entre diferentes comunidades serão produzidas.

Estes pressupostos da perspectiva construcionista do conhecimento trazem uma série de implicações para o fazer científico. A primeira delas é a modificação da concepção de conhecimento como representação. $\mathrm{Ou}$ seja, o conhecimento deixa de ser visto como originado na mente individual, e passa a ser entendido como produzido na relação entre as pessoas. A segunda implicação é que esta concepção de conhecimento traz uma crítica às ciências empiricista e idealista, marcadas por uma dualidade sujeito-objeto e seu conflito interminável. Apoiado nas críticas da sociologia do conhecimento e do pensamento feminista sobre o fazer científico, o construcionismo aponta para a superação da dicotomia sujeito-objeto. Como terceira implicação, entendemos que ele produz um questionamento sobre a natureza do real, impondo uma nova reflexão sobre o que vem a ser a verdade e a objetividade. Estas são repensadas a partir de critérios éticos, de coerência, inteligibilidade, rigor e conseqüências trazidas pelo conhecimento gerado. Estes pressupostos reforçam, portanto, uma visão de ciência enquanto produção sóciohistórica, questionando uma retórica da verdade objetivista, universalizante e aistórica.

\section{A Centralidade da Linguagem}

Uma outra implicação desta concepção construcionista é privilegiar o estudo da linguagem enquanto constituinte de práticas sociais na investigação sobre a produção do conhecimento em Psicologia deixando de focalizar o estudo da mente individual. A linguagem é considerada como atividade compartilhada, e sua análise deve focalizar o relacionamento entre as pessoas, e não o indivíduo, como produtor da linguagem e do entendimento. Segundo Gergen (1997), é "através da coordenação relacional, [que] nasce a linguagem, e através da linguagem nós adquirimos nossa capacidade de nos fazermos inteligíveis. O relacionamento substitui então o indivíduo como unidade fundamental da vida social" (Gergen, 1997, p. 253).

De acordo com esta forma de conceber a linguagem, é através dos momentos interativos entre as pessoas, nos quais elas têm que continuamente reagir umas às outras espontânea e praticamente, através de uma compreensão ativa e responsiva, que se poderá compreender como as pessoas se constróem. A ênfase é posta no estudo do processo de conhecer e responder ativamente às outras pessoas.

Esta visão da produção do significado traz a dialogia, a relação com o outro, como fundamento da vida humana. Nas palavras de Bakhtin (1984, p.287):

"Ser significa comunicar... ser significa ser para o outro, e através do outro, para alguém. Uma pessoa não tem um território interno independente, ela está completamente e sempre na fronteira; olhando para dentro de si, ela olha nos olhos do outro ou com os olhos do outro."

Nesta mesma perspectiva dialógica, Gergen (1997) propõe algumas bases para uma teoria relacional da produção do significado, quais sejam:

a) A significação não tem origem em uma mente individual que se expressa, mas é dada por uma história de relacionamento na qual determinados significados servem para coordenar as ações humanas.

b) O significado se constrói na relação entre as pessoas e assim, os enunciados só começam a ter significado 
quando outros adicionam alguma forma de ação suplementar, linguística ou não. Não se trata de uma relação de ação-reação, mas de ação conjunta.

c) A suplementação, por um lado, garante um potencial de significação para o enunciado, fazendo-o significar de uma forma específica, mostrando sua diferença em relação a outro significado. Por outro lado, ao significar de uma maneira dentre as possíveis, a suplementação delimita a significação cerceando seu potencial.

d) Uma suplementação não fixa determinado significado, tendo apenas um caráter temporário, estando sujeita a uma nova suplementação. Isto faz com que uma suplementação esteja aberta a novas significações em um processo de negociação de um relacionamento do qual esta ação de suplementação faz parte.

e) O processo de significação não é determinado apenas pela relação imediata entre as pessoas que 'produzem sentido', mas pelo conjunto de outros relacionamentos dos quais estas pessoas participam e já participaram. À medida que nos comunicamos com pessoas com as quais não nos relacionávamos, estas passam a suplementar nossos padrões de relacionamento, modificando potencialmente os sentidos aí construídos. A potencialidade de significação está referida, em última instância, às condições relacionais da sociedade em que vivemos.

f) As ações têm significado dentro de seqüências relativamente estruturadas. Assim, as pessoas desenvolvem uma 'ontologia' à medida que compartilham determinadas descrições do mundo que levam à coordenação das ações aí pertinentes e que possibilitam, então, a continuidade de seus relacionamentos. Trata-se de uma ontologia relacional, marcada por um conjunto de definições comuns que orientam expectativas e pemitem ações congruentes.

g) Tendo apontado como a coordenação das ações, as ontologias e portanto o entendimento entre as pessoas se desenvolvem, é importante também entender como se dá o desentendimento entre as pessoas. Entendimento e desentendimento são padrões de coordenação mútua descritos em nossa sociedade conforme alguns propósitos sociais. Descrever determinada interação como locus de desentendimento, é um processo cultural que varia de sociedade para sociedade. Além disso, o processo de entendimento-desentendimento está relacionado à criação de determinadas ontologias relacionais, que são circunscritas a certos relacionamentos, em contextos específicos, e que não preparam necessariamente para outros contextos, podendo, neste sentido, gerar desentendimento. À medida que as pessoas se relacionam, entram em contato com novos contextos e sentidos que ressignificam relacionamentos anteriores. Esta potencialidade para novas significações, novas seqüências de ações, traz consigo a diferença e o risco permanente do desentendimento. O próprio funcionamento da cultura, ao produzir ao mesmo tempo, centralização e dispersão de sentidos, gera definições do que o mundo é e do que o mundo não é, ou seja, possibilidades de entendimento e desentendimento.

\section{A Produção do Self}

Esta teoria relacional e dialógica da construção do significado tem implicações ontológicas relativas à definição do eu, à produção do self, que, nesta perspectiva, é considerado "uma expressão, um ser e um devir através da linguagem e da narração" (Goolishian \& Anderson, 1996, p.195). Para o construcionismo, então, o self não é compreendido como algo estável e duradouro, existente no interior do ser humano, mas como um fenômeno narrativo. Ou seja, "o produto de narrarmos histórias uns aos outros e a nós mesmos acerca de nós, e as que outros narram para nós e sobre nós" (Goolishian \& Anderson, 1996, p. 195). O self deixa de estar referido a uma estrutura pessoal privada e passa a ser entendido como um discurso que ocorre em contextos relacionais.

Assim, ao deslocarmos nossa atenção para o processo de comunicação, para o diálogo e o espaço de conversação, o self emerge enquanto uma atividade relacional. Isto é, algo sendo construído em relacionamentos, naquilo que as pessoas estão fazendo juntas e, portanto, delimitado pelas contingências destes relacionamentos. Marca-se então que alguns sentidos são possíveis e outros impedidos no processo interativo. É o que as pessoas fazem juntas que viabiliza a existência de determinadas linhas de ação e interpretação. Nas palavras de Gergen “(...) a narrativa de self é um implemento lingüístico fixado em seqüências convencionais de ação e empregadas nos relacionamentos de forma a sustentar, promover ou impedir diversas formas de ação" (1994, p. 188).

Esta visão relacional do self socialmente construído na linguagem, descentra o indivíduo como autor único de si mesmo, sendo compreendido como uma construção social de múltiplos autores. As narrativas sobre si mesmo, tal como outras narrativas sobre o mundo, sempre comportam múltiplas vozes.

Neste mesmo processo de construção do eu também se constrói o outro. As narrativas de self sempre incluem descrições a respeito do outro, o qual também é construído por esta narrativa. Contudo, dado que a validade narrativa destas descrições é produzida concretamente através das interações sociais, o outro 
precisa tanto aceitar a descrição a respeito de si mesmo, bem como o lugar reservado a ele nesta narrativa. Cria-se assim, socialmente, uma 'rede de identidades recíprocas', cuja trama sensível pode ser mudada assim que qualquer um dos participantes se modifica. Deste ponto de vista, uma identidade nunca é individual, mas dependente de um conjunto de relacionamentos (Gergen, 1997).

Esta co-autoria na produção do self através da conversação nos aproxima de um outro conceito que versa sobre as implicações identitárias de determinados sentidos produzidos nas interações, ou seja, de como o self é produzido discursivamente. Este conceito é o de posicionamento. Desta perspectiva, “(...) um indivíduo emerge através dos processo de interação social, não como um produto final relativamente fixo, mas como alguém, que é constituído e reconstituído através das práticas discursivas nas quais participa" (Davies \& Harré, 1990, p. 46).

Há assim, uma multiplicidade de selves, coerentes e contraditórios, que são articulados por nós em cada momento segundo as exigências de uma conversa. A cada conversação, ao fazer escolhas ativas entre demandas muitas vezes contraditórias, buscamos recortar a diversidade que nos constitui para a produção de uma história de nós mesmos que é unitária e consistente. Nesta busca nos apoiamos no significado emocional das posições possíveis, nas estórias através das quais determinadas categorias e emoções fazem sentido e no sistema moral que legitima tais escolhas (Davies \& Harré, 1990). Não há uma história de vida única a ser contada.

Contudo, há uma demanda cultural para uma narrativa de self estável. Em determinadas negociações da vida social é necessário fazer-se compreender como portador de uma identidade coerente, integrada e durável. A identidade pessoal, assim, é resultado dos relacionamentos que a exigem. Em termos narrativos, as pessoas podem se apresentar de diferentes formas dependendo do contexto relacional, tendo muitas vezes que produzir narrativas de estabilidade, bem como de mudança. As narrativas de self perdem assim sua aparência monológica e explicitam o caratér sempre dialógico de sua produção.

Desta perspectiva, a possibilidade de mudança do self, conforme Anderson (1997, p. 233), é inerente ao diálogo:

“(...) mudança é o contar e recontar de histórias familiares;

são as redescrições que se desenvolvem através da conversação; são os diferentes significados que são dados nos eventos e experiências passados, presentes e imaginados no futuro. A mudança se torna o desenvolvimento de futuros selves."

Trata-se, portanto, de uma visão na qual qualquer possibilidade de mudança e de estabilidade de determinada descrição está referida à constituição e dinâmica da trama de relacionamentos interpessoais na qual a pessoa está inserida.

\section{A Psicoterapia Construcionista}

O construcionismo se faz presente no campo da psicoterapia a partir de uma série de críticas e insatisfações que impregnavam e ainda impregnam a pesquisa e intervenção em saúde mental. Entre outras críticas, podemos apontar, segundo McNamee e Gergen (1998), o reconhecimento de vieses ideológicos nas teorias e práticas psicoterápicas que atuam na manutenção de determinado status quo; o deslocamento do indivíduo como centro de disfunções para abranger o funcionamento das unidades familiares; a valorização de contextos sociais mais amplos na determinação da 'patologia individual'; a desconsideração das pressuposições do terapeuta na construção da descrição sobre a realidade e da interpretação terapêutica; as críticas feministas e de ex-pacientes de problemas mentais a respeito da opressão e da objetificação promovidas pelos sistemas de classificação de doenças.

A partir destas várias críticas, as propostas socioconstrucionistas, ligadas ao pensamento pósmoderno, vêm promover uma redefinição do modo de operar da psicoterapia. Segundo Gergen (1997), estas mudanças estão referidas ao foco da ação em psicoterapia, ao relacionamento entre terapeuta e cliente e à redefinição do que vem a ser a doença e sua cura.

Assim, o foco da ação terapêutica não está voltado para os processos mentais e enfatiza a análise dos processos microssociais. A terapia marcada por uma influência construcionista tira o foco do 'interior' da pessoa, suas cognições e constructos individuais, e enfatiza seu discurso em uma visão da linguagem como um processo social. Outros conceitos passam a ter importância na prática psicoterápica, como os de metáfora, formas narrativas (Gergen \& Gergen, 1988), dialogismo (Anderson, 1997; Bakhtin, 1997) e posicionamento (Davies \& Harré, 1990).

A relação terapeuta-cliente busca a equalização e a coconstrução. O conhecimento trazido pelo terapeuta não é hierarquicamente superior ao trazido pelo cliente. Ele não tem a verdade sobre o outro, mas traz diversos modos de ser, de falar e descrever as situações, que podem, em um processo de colaboração e co-construção, se tornarem alternativas úteis para as construções do cliente.

A definição do que vem a ser a doença e a cura perdem seu privilégio ontológico à medida que se focaliza a construção social da realidade. A perspectiva construcionista busca examinar a natureza contingente das 
construções sobre doença e cura, as implicações destas, e a possibilidade de construções alternativas, reconhecendo a participação do terapeuta e do cliente na cultura.

Estas mudanças propostas na prática psicoterápica estimulam conversações dialógicas, nas quais, através do cultivo da curiosidade (Gergen \& Kaye, 1998), da reflexividade (Andersen, 1999), do partilhar os pensamentos com o cliente (Cecchin, 1998; Lax, 1998), da introdução da diferença e da proposição de novas formas de descrição dos eventos (Fruggeri, 1998), buscase a construção de novas narrativas no processo de produção do self.

Contudo, o que importa no processo psicoterápico não são apenas as formas alternativas surgidas no diálogo com o outro mas também o aparecimento de uma nova ordem de sentido em tais possibilidades. Neste processo, a ênfase não está posta na produção de mudanças, mas antes de tudo, na abertura de espaços para conversação. Para isso é necessário, segundo Gergen e Kaye (1998), um diálogo transformador em que se negociem novos entendimentos, bem como premissas a respeito do sentido.

Para Anderson, o resultado de uma terapia exitosa está relacionado à liberdade e esperança promovidas pela sensação de auto-agenciamento (self-agency) na produção das narrativas de self. Tal sensação pode ser produzida através da construção de novas narrativas em primeira pessoa que permitam o contar de "uma nova história que seja mais tolerável, coerente, e contínua com a intenção presente" (1997, p. 231).

\section{O Construcionismo no Campo da Psicoterapia de Grupo}

Apesar das inúmeras contribuições que têm ocorrido no campo da psicoterapia individual, e especialmente da psicoterapia familiar, referentes às implicações das concepções construcionistas para a prática psicoterápica (Anderson; 1997; Friedman, 1993; McNamee \& Gergen, 1998; Owen, 1992), são escassos trabalhos que busquem analisar como se redimensionaria a psicoterapia de grupo a partir de tal perspectiva.

Teoricamente, a perspectiva construcionista traria à prática grupal algumas das transformações já produzidas no campo da terapia individual e familiar, ou seja, a ênfase nos processos microssociais, a equalização terapeutacliente, e o desontologizar a doença. Além disso, outras transformações seriam necessárias, dada a especificidade do dispositivo grupal, relacionadas à própria conceituação de grupo, ao seu suposto caráter unitário, ao lugar do discurso e da produção de sentido.
Estudando um grupo de apoio para pessoas portadoras do HIV (Rasera, 1999), no qual utilizamos diversas concepções produzidas por pensadores construcionistas (Davies \& Harré, 1990; Gergen, 1985, 1997; Spink, 1999), pudemos observar como tais concepções redimensionam e podem produzir uma nova descrição da prática grupal. À medida que o self não é concebido como algo existindo na mente das pessoas, mas como algo construído na esfera da conversação, do diálogo e do discurso social, como propõem os construcionistas, o grupo constitui-se como um espaço privilegiado de construção do self e de análise desse processo uma vez que ele possibilita trazer para primeiro plano o aspecto dinâmico, relacional e de múltipla autoria do processo de negociação das descrições de self e da vida entre os participantes.

Em nossa leitura socioconstrucionista da psicoterapia de grupo, enfocamos o processo de negociação entre os participantes, buscando compreender como são desconstruídos alguns significados produzidos entre os participantes, e como são construídos novos sentidos e narrativas sobre a vida e as coisas do mundo. No estudo desse grupo enfatizamos o processo comunicacional, no qual a análise do dialogismo da produção discursiva constituiu um aspecto central, trazendo para primeiro plano as múltiplas relações dialógicas existentes intra e interlocutores e dando vOz aos múltiplos eus que se defrontam na psicoterapia de grupo. O movimento grupal, a partir desta perspectiva, foi referido concretamente a um conjunto de interações verbais marcadas pelo conjunto de influências sociais presentes no dizer dos interlocutores e pelas relações aí construídas.

\section{Análise de uma Sessão de Psicoterapia de Grupo}

A partir das proposições apresentadas até aqui, utilizaremos de fragmentos de uma sessão para exemplificar algumas implicações do pensamento construcionista para o estudo dos grupos. A sessão aqui apresentada é a de um grupo de apoio aberto para pessoas portadoras do HIV. Trata-se de um atendimento público, que ocorre semanalmente e tem o objetivo de facilitar a construção grupal de uma outra relação dos portadores do HIV com as descrições de soropositividade trazidas pelos mesmos. O terapeuta atua de forma a estimular conversações dialógicas, promovendo o acolhimento, o exercício da reflexividade e a construção de novas descrições das situações trazidas pelos participantes. Esta sessão teve duração de uma hora e trinta minutos, na qual estiveram presentes quatro participantes conjuntamente com o terapeuta: Maria e Marcos, que já haviam participado do serviço por várias vezes, Ana, que 
participava pela segunda vez e Carlos, pela primeira. Nesta sessão, Marcos chega atrasado. Há uma tensão entre os participantes que negociam ativamente suas diferentes descrições do viver com HIV/aids, pautados por uma lógica de culpabilização/vitimização.

Metodologicamente, a análise foi marcada pela operacionalização dos conceitos de dialogismo e posicionamento, centrais para uma pesquisa/prática inspirada no construcionismo. Esta operacionalização se reflete nos seguintes passos:

1) Leitura exaustiva da transcrição da sessão escolhida;

2) Análise seqüencial de todo o material transcrito: inicialmente, resumimos a transcrição da sessão, mantendo o número de turnos, de falas de cada participante durante a mesma. Então, colorimos as falas de cada participante com uma cor, possibilitando visualizar de forma global as seqüências das falas dos participantes, a interação entre eles.

3) Construção de eixos processual e temático: a partir das leituras construímos eixos de análise que permeavam a construção dos sentidos nos diversos momentos da sessão: eixos processual e temático. Este último se refere ao objeto de discussão das conversas grupais, os conteúdos, os assuntos, os sentidos. O eixo processual se refere ao ato que tal discussão promovia, ou seja, aproximação, distanciamento, atenção, indiferença entre os participantes. A análise através do eixo processual fez nascer um sentido outro para as diversas temáticas desenvolvidas na sessão.

4) Construção de delimitações temáticos-seqüenciais: as delimitações temático-seqüenciais constituem recortes seqüenciais de momentos da interação grupal que indicavam como se davam algumas formas de construção dos sentidos. Eles eram marcados por uma temática e uma duração no tempo. Cada momento consistiu de um conjunto de enunciados no qual havia uma disputa pelos sentidos que determinada questão trazia, produzindo uma ampliação ou restrição dos significados até ali enunciados. Estes recortes permitiram focalizar o caráter de negociação das trocas que ocorreram na sessão, bem como a instabilidade e complexidade da sessão em seus diversos momentos.

5) Análise das posições e jogos de posicionamentos: buscamos rastrear as diversas posições pessoais e morais existentes nas negociações ocorridas no interior de cada momento e ao longo da sessão, o que nos permitiu visualizar as transformações na construção discursiva dos participantes na sessão, e assim algumas contribuições deste tipo de atendimento na vida destas pessoas.

Através destes diversos procedimentos analisamos a referida sessão de grupo. A partir da leitura exaustiva do material e da análise seqüencial, construímos um eixo processual denominado 'negociação da diferença' e dois eixos temáticos denominados 'ser soropositivo' e 'encontrar apoio'. Concomitante à criação destes eixos, a sessão foi delimitada em 10 momentos. Por efeitos de restrição de espaço, apresentaremos 3 momentos significativos na interação grupal por possibilitar descrever o dialogismo intra e inter momentos da sessão, bem como o jogo de posicionamentos em diferentes momentos.

\section{Momento 1 \\ O Estranho que Chega}

Este é o momento inicial do grupo no qual estão presentes o terapeuta, Carlos, Ana e Maria. Neste momento é realizado o contrato no grupo, delimitando as possibilidades narrativas do eu. Durante o estabelecimento do contrato, Carlos se apresenta ao grupo como Carlos-que-sabe-tudo-de-tratamento-psicológico e Carlos-que-foi-expulso-de-um-serviço-de-saúdemental.

"Conheço este tipo de trabalho. Eu já fui no A (hospital psiquiátrico da região), eu já fui internado três vezes lá (...), então eu conheço tudo o trabalho dos psicólogos (...) Eu conheço tudo"

"Só me expulsaram de lá porque um rapaz (...) quis crescer pro meu lado. Levantou. Aí eu peguei e parti pra cima dele, não ia deixar pegar eu não. Aí eu peguei e meti a mão nele lá dentro. Aí eles expulsaram eu de lá."

Sinal de ameaça ao grupo que faz o terapeuta se perguntar: com quem é possível trabalhar neste grupo? O que trabalhamos aqui? De que forma? Ele reafirma o contrato, especificando algumas características daquele trabalho e das pessoas ali envolvidas.

"O que a gente fala? No que que eu posso ajudar? Esse é um grupo para pessoas portadoras do HIV. O que que a gente conversa? Geralmente, sobre a vida das pessoas, né, e o que que ela tem, o que que a questão do HIV, da aids mudou na vida das pessoas né. Então aqui acaba sendo um lugar que essas pessoas conseguem falar um pouco, se aliviar e daí ficar com força pra levar a vida (...)"

(...) pra conhecer um pouquinho as dificuldades que o Carlos tem enfrentado, né, umas dificuldades um pouco diferentes das outras pessoas que estão aqui viu Carlos, eu já lhe adianto um pouco isso, né."

É importante observar ainda como o terapeuta e Carlos vão redirecionando suas perguntas e respostas, ou seja construindo a realidade grupal, a partir da interação entre ambos. Descrevem a si próprios e ao serviço de acordo com as demandas do contexto, da forma como antecipam a reação do outro, em um processo dialógico de mútua determinação. Trata-se de um processo de posicionamento no qual contribuem a presença de vozes 
já ouvidas por eles em suas vidas, em outros atendimentos grupais do terapeuta e em outros atendimentos nos quais Carlos participou. A dialogia que articula diferentes vozes das múltiplas experiências dos participantes e dos contextos extra-grupais.

Há um duplo sentido no contrato proposto pelo terapeuta, a partir da fala de Carlos e da reação dos outros participantes em relação a ele: aproximação das diferenças, facilitando a interação entre os participantes e afirmação de uma distinção entre Carlos e os outros do grupo. Este contrato contribuirá na determinação das possibilidades de outras descrições sobre o viver com HIV para os participantes.

\section{Momento 6}

\section{A Diferença Explicitada: Guinada na Sessão}

Até este momento, passada mais da metade da sessão, se produziu a aproximação de Marcos, Maria e Ana, através da semelhança do posicionamento de vítimas frente à vida com aids. A inserção de Carlos na sessão tem sido dificultada pela posição contrária sustentada por este. Conversam, neste momento, sobre o apoio familiar e a revelação da soropositividade. A partir dos comentários de Ana sobre a falta de apoio do ex-marido, e seu isolamento social, Carlos-responsável se posiciona quanto à revelação da soropositividade:

"Eu vou ser sincero, eu, aonde eu moro ali, todo mundo sabe que eu tenho. Eu nunca menti pra ninguém, eu falei 'eu tenho, eu portei, eu procurei, e eu vou assumir"'.

Fala que, em um jogo de posicionamentos, faz dos outros participantes do grupo, que não revelaram o status de soropositividade, serem considerados irresponsáveis. Tensão na sessão. Necessidade de combater determinados sentidos decorrentes da fala de Carlos.

"Mas aí a gente tem criança pequena, os filhos da gente também podem sofrer". (Maria, em tom confrontativo)

"Isso..." (Ana fala ao mesmo tempo)

"Os meus filhos todos sabem que eu tenho a doença". (Carlos)

"Mas os seus filhos são grandes, os da gente são pequenos e nasceram com o HIV". (Maria)

"Eu sofro muito sabe, pelo meu filho, e eu sei que um dia ele, ele vai crescer né, eu tenho muita esperança nisso porque por enquanto ele tem". (Ana)

A recusa a este posicionamento como irresponsável se dá, para estas duas mulheres, pela afirmação de uma outra responsabilidade: a de cuidar dos filhos para que estes não sejam discriminados. A voz da maternidade neste jogo de posicionamentos produz para Ana e Maria uma posição de culpada. Afirmar a responsabilidade pela proteção dos filhos é afirmar a responsabilidade por sua infecção. Neste momento, elas ocupam simultaneamente a posição de vítimas (mulheres-infectadas-pelos-parceiros) e de culpadas (mães-que-transmitem-HIV-aos-filhos). No posicionamento frente à infecção pelo HIV, diferentes relações (marido-mulher x mãe-filho) implicam diferentes posições (vítima x culpada). Neste momento ocorre uma transição de posições na dialogia do movimento grupal.

\section{Momento 8 \\ O Estranho em Nós}

Decorrente da conversa sobre a revelação da soropositividade, no momento sete, passam a discutir a questão da cura da aids, o que gera uma tensão ainda maior. O terapeuta tenta aproximar os participantes. Neste momento oito, ele investiga entre os participantes como é viver sabendo que essa doença ainda não tem cura.

Surge então, Carlos-com-pouco-tempo-de-vida. No processo desta sessão completa-se a construção da vitimização de Carlos.

“(...) eu tenho pouco tempo de vida, eu não sei quanto. Quer dizer, então agora, tá na mão de Deus e eu tô esperando, tô vivendo o meu dia-a-dia, quando eu acordo eu dou um grande sorriso e agradeço a Deus por ter me acordado e é só isso"

Ao mesmo tempo, surgem as mães-culpadas, retomando-se alguns sentidos dos momentos 5 e 6 , bem como Marcos-culpado:

"A maior pessoa culpada é eu". (Marcos)

“(...) eu olhava pra ele [o filho], eu falava 'Gente, mas

Deus tá me castigando tanto, tanto, será que eu tô merecendo tudo isso? Descobri na minha gestação que eu sou portadora do HIV, meu filho". (Ana)

"A gente se culpa né ... a gente se culpa muito. A gente passa a gravidez inteira se culpando". (Maria)

Ao longo da sessão, há um reposicionamento entre os participantes: a vitimização de Carlos e culpabilização dos outros. O desconforto, o estranhamento sentido em relação às narrativas de Carlos pelos outros participantes da sessão, parecem agora também estar presentes nas narrativas a respeito de si mesmos. Maria, Ana e Marcos também se posicionam como culpados. $\mathrm{O}$ discurso da vítima/culpado permeia a construção da soropositividade e seu entendimento. As diferenças entre os membros do grupo, tão buscadas e apontadas, marcadas por uma lógica da culpabilização deixam, depois desse momento, de ser o centro no espaço das relações interpessoais. Carlos posicionado como vítima não demanda embate e negociação.

Essa forma de análise nos permitiu acompanhar o processo de negociação dos sentidos e das descrições de si próprio nos diferentes momentos da sessão. 


\section{A Atenção à Negociação e à Construção dos Participantes}

Comparativamente a outras formas de pensar e intervir em grupo, esta forma de análise permite substituirmos uma ênfase unitária, seja no indivíduo, seja no grupo, por um reconhecimento da multiplicidade. Assim, o entendimento do que ocorre no grupo não precisa ser buscado nas realidades mentais de cada participante do grupo, nem em um movimento grupal, resultado de algum processo que o transcende.

O foco no processo comunicacional aproxima o movimento grupal do movimento discursivo, ou seja, o entendimento do grupo decorre do acompanhar as suplementações que ocorrem a partir da expressão de cada participante. Este acompanhar as suplementações se traduz em uma postura de atenção à negociação dos sentidos e das diferenças na conversação.

Esta atenção à negociação mostra como os sentidos são determinados pelos lugares de cada participante na sessão e pela significação social das versões e descrições aí negociadas. O foco se torna a dialogia existente nesta produção de sentido que se presentifica pelas vozes sociais, pelos diferentes discursos que povoam a realidade que vivemos. O grupo é, assim, entendido como constituído de inúmeras conversas que se dão intra e interlocutores, bem como com os discursos sociais mais amplos.

Esta forma de pensar grupo o situa dentro das possibilidades e limites dos repertórios sociais de descrição da realidade, tornando a prática grupal mais sensível a estes repertórios que atravessam o grupo, tirando de foco seja o indivíduo, seja o grupo, como realidade privilegiada. A ênfase está voltada para o processo de construção da realidade e de si mesmo através das possibilidades de negociação existentes nas relações grupais.

Assim, associada a esta postura de atenção à negociação, à ênfase na dialogia, está a análise da construção das pessoas através de sua participação no grupo, ou seja, os diversos posicionamentos tornados possíveis nesta relação grupal.

A cada apresentação dos participantes, cada vez que descreviam uma postura, ação ou pensamento, de si próprios ou de outros ali presentes, uma possibilidade narrativa do self era posta para ganhar novos sentidos, ser expandida, ampliada ou permanecer restrita e calada. Nas conversas grupais os participantes negociavam descrições de si próprios bem como dos outros, em um processo nem sempre intencional.

Podemos observar como Carlos se posiciona logo no momento inicial da sessão como Carlos-que-sabetudo-de-tratamento-psicológico e depois como Carloscom-pouco-tempo-de-vida. Posições que ele se coloca.
Contudo, ele também coloca os outros em determinadas posições. No momento 6 , ele posiciona aqueles que não revelaram publicamente a soropositividade como irresponsáveis. Este processo de posicionamento demanda negociações. Os outros participantes reagem a este posicionamento.

Nos diferentes momentos podemos também observar uma mudança de posicionamentos morais. Carlos passa de responsável pela própria vida, pela infecção pelo HIV para uma posição de alguém que espera a morte, da qual nada depende dele.

É a interação com o outro que possibilita que esta descrição de self seja estabilizada em alguns relacionamentos e se transforme em outros. $\mathrm{Na}$ análise destes momentos da sessão pudemos observar que houve uma mudança de posicionamentos, que outras possibilidades de descrição de si, outras formas de olhar para si e para a vida com HIV se fizeram presentes na sessão.

Através desta análise podemos compreender como:

a) uma sessão de grupo é marcada por uma série de negociações entre seus participantes;

b) a possibilidade de negociação entre determinadas descrições do self e da vida é marcada pelo valor social nelas embutido e pela posição ocupada por cada participante na sessão;

c) a homogeneidade grupal, antes de ser um critério organizador da composição do grupo, é algo construído na interação grupal;

d) as intervenções de cuidado ao portador do HIV estão vinculadas a processos sociais mais amplos relativos à discriminação existente em torno da aids.

\section{Outros Desenvolvimentos}

Este texto esboça algumas implicações do pensamento construcionista para o estudo e a prática grupal, apontando para o caráter construído do grupo e seu processo de negociação, a perspectiva discursiva de construção das pessoas e portanto do processo de construção da homogeneidade grupal, e as delimitações sociais destes processos de construção no grupo.

Se por um lado, as compreensões produzidas a partir desta análise nos mostram o caráter dinâmico, fluido, situacional e relacional da produção do self, outras leituras devem ser realizadas para que se possa também entender a permanência, a repetição, a estabilidade de algumas formas de descrição do self, e como a situação grupal cria contexto para tais (re)produções.

Nesta tarefa, a dimensão temporal da produção do self e da intervenção grupal ganha destaque. Novos entendimentos sobre a processualidade grupal, sua 
continuidade-descontinuidade, devem ser construídos para que se estude a dialogia da produção de narrativas do self ao longo de um conjunto de sessões e se compreenda a articulação complexa entre os tempos da intervenção grupal e da produção do self.

Além disso, questões ainda por serem desenvolvidas em uma abordagem construcionista no campo da psicoterapia individual e familiar, também o são na psicoterapia de grupo, tais como a transferência dos 'efeitos terapêuticos' para outros contextos, a ética das descrições produzidas nas sessões, e a política das relações entre terapeuta e participantes e destes entre si. No estudo dos grupos, outras concepções clássicas, como as de cultura grupal e desenvolvimento do grupo, podem ser problematizadas. Além disso, desenvolvimentos teóricos que produzam conceitos que norteiem as intervenções do terapeuta para o manejo de negociações entre vários participantes ao mesmo tempo, como ocorre no contexto da psicoterapia de grupo, permanecem como desafio para novos desdobramentos.

\section{Referências}

Andersen, T. (1999). Processos reflexivos (R. M. Bergallo, Trad.). Rio de Janeiro: Instituto NOOS/ITF.

Anderson, H. (1997). Conversation, language and possibilities. New York: BasicBooks.

Bakhtin, M. (1984). Problems of Dostoevsky'spoetics (C. Emerson, Trad.). Minnieapolis: University of Minnesota Press.

Bakhtin, M. (1997). Marxismo e filosofia da linguagem (M. Lahud \& Y. F. Vieira, Trad.). São Paulo: Hucitec.

Cecchin, G. (1998). Construindo possibilidades terapêuticas (C. O. Dornelles, Trad.). Em S. Mcnamee \& K. J. Gergen (Orgs.), A terapia como construção social (pp. 106-116). Porto Alegre: Artes Médicas.
Davies, B. \& Harré, R. (1990). Positioning: The discursive production of selves. Journal for the Theory of Social Behaviour, 20(1), 44-63.

Friedman, S. (Org.) (1993). The new language of change. New York: Guilford Press.

Fruggeri, L. (1998). O processo terapêutico como construção social da mudança (C. O. Dornelles, Trad.). Em S. Mcnamee \& K. J. Gergen (Orgs.), A terapia como construção social (pp. 51-65). Porto Alegre: Artes Médicas.

Gergen, K. J. (1985). The social constructionist movement in modern psychology. American Psychologist, 40, 266-275.

Gergen, K. J. (1997). Realities and relationships. Cambridge: Harvard University Press.

Gergen, K. J. (1999). An invitation to social construction. London: SAGE.

Gergen, K. J. \& Gergen, M. M. (1988). Narrative and the self as relationships. Advances in Experimental Social Psychology, 21, 17-48.

Gergen, K. J. \& Kaye, J. (1998). Além da narrativa na negociação do sentido terapêutico (C. O. Dornelles, Trad.). Em S. Mcnamee \& K. J. Gergen (Orgs.), A terapia como construção social (pp. 201-222). Porto Alegre: Artes Médicas.

Goolishian, H. A. \& Anderson H. (1996). Narrativa e self: Alguns dilemas pós-modernos da psicoterapia (J. H. Rodrigues, Trad.). Em D. F. Schnitnam (Org.), Novos paradigmas, cultura e subjetividade (pp. 191-203). Porto Alegre: Artes Médicas.

Lax, W. (1998). O pensamento pós-moderno na prática clínica (C. O. Dornelles, Trad.). Em S. Mcnamee \& K. J. Gergen (Orgs.), A terapia como construção social (pp. 86-105). Porto Alegre: Artes Médicas.

Mcnamee, S. \& Gergen, K. J. (Orgs.) (1998). A terapia como construção social (C. O. Dornelles, Trad.). Porto Alegre: Artes Médicas.

Owen, I. R. (1992). Applying social constructionism to psychotherapy. Counselling Psychology Quarterly, 5, 385-402.

Rasera, E. F. (1999). Grupo de apoio para pessoas portadoras do HIV: Negociando diferenças. Dissertação de Mestrado não-publicada, Curso de PósGraduação em Psicologia, Universidade de São Paulo. Ribeirão Preto, SP.

Spink, M. J. P. (Org.) (1999). Práticas discursivas e produção de sentido no cotidiano. São Paulo: Cortez.

Recebido em 24/11/2000

Revisado em 18/01/2001

Aceito em 14/02/2001

Sobre os autores:

Emerson F. Rasera é professor da Universidade de São Paulo em Riberião Preto.

Maria Japur é professora da Universidade de São Paulo em Ribeirão Preto. 